\title{
Improving Knowledge Sharing Through Idealized Influence Leadership Case from Private Universities in Central Java Indonesia
}

\author{
Suhana \\ Management Department \\ Universitas Stikubank \\ Semarang Indonesia \\ suhana@edu.unisbank.ac.id \\ Askar Yunianto \\ Management Department \\ Universitas Stikubank \\ Semarang Indonesia \\ askar@edu.unisbank.ac.id
}

\author{
Hasan Abdul Rozak \\ Management Department \\ Universitas Stikubank \\ Semarang Indonesia \\ hasanarozak@edu.unisbank.ac.id
}

\author{
Lutfika Rachmawati \\ Management Department \\ Universitas Stikubank \\ Semarang Indonesia \\ lutfikarachmawati@edu.unisbank.ac.id
}

\begin{abstract}
The aim of the current research is to examine and to analyze the role of idealized influence and contingent reward leadership to knowledge sharing. The ground of the current research is that most of transformational leadership researches focused on 4 dimensions as composite dimensions. Thus, the contribution of each dimension is not clearly described. Meanwhile a leader can just have many, not all, dimensions of transformational leadership. Idealized influence, one of dimensions of transformational leadership is supposed to be predictor of knowledge sharing. Idealized influence leadership builds trust to subordinates and it is main prerequisite for sharing knowledge. The object of the research is private universities in central java having superior accreditation (A accredited). Populations are all lecturers in $\mathbf{5}$ universities having had educator certificate. Sample of the current research is $\mathbf{1 6 2}$ lectures from 5 universities. Sampling technique is non probability sampling. Regression analysis is used to examine the hypotheses. Based on analysis conducted, idealized influence leadership significantly affect to knowledge sharing, while contingent reward leadership does not affect to knowledge sharing. The current research gives theoretical contribution by giving more evidence of the effect of idealized influence leadership to the knowledge sharing. For practical contribution, an organization should develop idealized influence leadership through intensive training to improve knowledge sharing. The current research has many limitations. The object is only private universities so that the finding cannot be generalized to state universities. Future research can compare between private and state universities to give comprehensive understanding concerning how knowledge sharing activities are encouraged. Future research can use other dimensions of transformational leadership to give better understanding of contribution of each dimension to knowledge sharing.
\end{abstract}

Keywords: knowledge sharing, idealized influence, contingent reward, private universities

\section{INTRODUCTION}

Recently, organization operates in very fast changing environment. Organizations should formulate strategies to sustain their life through their resources. Organizational resources can be tangible and intangible ones. From literature study, it is indicated that intangible resources give much more contribution to the gaining of organizationally competitive advantage. Certain intangible resources owned by an organization can be unique in nature, scarce and difficult to imitate by competitors. Knowledge as one of intangible resources is predicted being able to give positive contribution to the organization.

Organizational knowledge plays pivotal role in assuring the sustainability of organization. Managing knowledge will be strategic choice to win in hard competition. In the context, knowledge management will be very relevant to discuss. Knowledge sharing is one of main elements of knowledge management. Knowledge sharing is concerning how knowledge is created, shared, stored and implemented. Optimum knowledge sharing has positive effect to some organizational outcomes, such as: performance and innovative behavior. Thus, knowledge sharing improving will be important to carry out.

Based on literature study, improving knowledge sharing can be through certain leadership style. Transformational leadership is predicted as main antecedent of knowledge sharing. The indication is in line with the research finding of [1] indicating that transformational leadership is as significant predictor of internal knowledge sharing. Besides, contingent reward transactional leadership is also predictor of knowledge sharing. [2] found that contingent reward transactional leadership affect to knowledge sharing. Combination of both with different stressing will positively affect to knowledge sharing activities. 
Most of researches concerning transformational leadership focus on four dimensions as composite dimensions. Therefore, contribution of each dimension will be clearly described. A leader can just have many characteristics, not all dimensions. Idealized influence leadership, one of transformational leadership dimensions is supposed to be good predictor of knowledge sharing. Idealized influence leadership builds subordinate's trust and the trust is main prerequisite of sharing knowledge. The research finding of [3] with research object in Iraq higher education showed that idealized influence leadership positively affected to knowledge sharing.

The indication is in line with research of [4] studying about how individual dimension in transformational leadership theory contributes to knowledge sharing. Researches focusing on the case is still scarce. Most of them investigated the role of the transformational leadership using four dimensions as composite dimensions [1]; [5]. It makes difficulties to identify contribution of each dimension to knowledge sharing. It is possible that a leader just has certain dimensions, not having all. It is also transactional leadership having three dimensions. A leader can have one or two characteristics of transactional leadership. There is an urgent need for scholars to make sure the effect of dimension of leadership theory to knowledge sharing. The current research fills this theoretical gap. Thus, the aim of the current research is to examine idealized influence transformational leadership and contingent reward transactional leadership to knowledge sharing.

\section{LITERATURE REVIEW}

\section{A. Knowledge Sharing}

Knowledge sharing constitutes one of important elements in knowledge management topic. It is in line with [6] stating that one of important matters in knowledge management is how to promote knowledge sharing effectively. Moreover, knowledge sharing is a main aspect of knowledge management researches. Knowledge sharing has a pivotal role for an organization to gain its competitive advantage. Knowledge sharing supports creativity, performance, efficiency and reputation [7]. Process and output of knowledge sharing in an organization can be scarce in nature and difficult to imitate by competitors. Knowledge sharing as an activities centering on knowledge is a main tool for employees to contribute to the knowledge application, innovation and in turn to the competitive advantage [8].

Knowledge sharing is process of sharing knowledge among employees within an organization. It is in line with the definition of [9] that knowledge sharing constitutes an element supporting organization to create knowledge and converts it to greater power. Other definition is from [10] that knowledge sharing is dessimination of information and knowledge through organization. Knowledge sharing plays pivotal role in organizational process because knowledge sharing helps organization transfer new ideas and solution [11]. When employees interact each other, the moment promotes knowledge sharing among them. From some definitions of knowledge sharing, it is concluded that basic characteristics of knowledge sharing are as follows: a) knowledge sharing is a main individual behavior, b) knowledge sharing is a voluntaire and proactive behavior awareness, c) knowledge sharing is controlled by system and procedure, like legal, ethic standard and behavior guidance, d) knowledge sharing result is for both parties or more [12].

\section{B. Idealized Influence Transformational Leadership}

[13] stated that transformational leadership happened when employees are interdependent in such away so that leader and his followers support each other to improve motivation and morality. Thus, transformational leadership has a role as independent power in conducting motivation change through the fulfillment of motive satisfaction. [14] built work of [13] and described transformational leadership in the case of the effect felt by followers. Followers are trusted and admired and loyal to their leader.

Tansformational leadership constitutes one of the most popular theories of leadership. Thus, transformational leadership is supposed as important topic in leadership for more than 20 years [15]. The interest is related with the fact that transformational leadership leads to positive relationship with followers and gives performance motivation and commitment. The leadership is also as an effective leadership. As additional, transformational leadership is supposed to be robust across condition and can be implemented in different culture [16]. Moreover, transformational leadership is related with some organizational outomes, such as: creativity, satisfaction, performance, organizational commitment and job withdrawal, organizational citizenship behavior and also absenteism [17]; [18].

Transformational leadership has 4 dimensions: idealized influence, inspirational motivation, intellectual stimulation and idealized consideration. Idealized influence is related with leader behavior as a model. A leader feels comfortable when interacting with followers. Leader prioritizes group interest, gets respect from followers. Besides, leader has good selfconfidence. While for inspirational motivation dimension, leader inspires and supports followers to recognize challenging job. Intellectual stimulation is related with attitude of leader giving new ways, new perspectives in solving the organizational problems. Meanwhile dimension of individualized consideration, a leader pays attention to followers individually.

\section{Contingent Reward Transactional Leadership}

Transactional leadership is one of leadership styles often found in business and industry [14]. The style is often used because it is effective in motivating employees to reach shortterm organizational objectives. The indication is in line with what was said by [19] that transactional leadership constitutes a leadership style often used in the current business. It is characterized by reward system for the employees meeting the the organizational goal. Transactional leadership style covers the exchange between a leader and the followers where both accept something valuable. Usually followers receive financial reward and the leader accepts the job directing to the organizational goal achievement.

Transactional leadership has three main characteristics. Firstly, transactional leader work with team members to gain specific and clear objectives and makes sure that followers received reward promised when meeting the objectives. 
Secondly, they exchange reward and reward promises to work hard. Finally, transactional leadership is responsive to followers's interest when the tasks have been accomplished [20].

Transactional leadership has three dimensions, namely: contingent reward, management by exception active and management by exception passive. Transactional leadership contingent reward is characterized as follows: 1) leader gives clearer description concerning what will be received by followers, 2) leader expresses satisfaction of followers's achievement, 3) leader gives reward for followers's good performance, 4) leader gives positive feedback of followers's performance, and 5) leader gives special recognition of followers's performance. From literature study, included previous researches, the effectivity of the dimension is higher than the other two. From previous researches review, contingent reward transactional leadership consistently has positive effect to knowledge sharing.

\section{Idealized Influence Transformational Leadership and Knowledge Sharing}

Transformational leadership is one of the most popular leadership styles having many specific characteristics. Leader suppresses on clarity in communicating the organizational goal, promotes new skill development of followers to develop organization [21]. Transformational leadership treats followers as valuable resource of organization and recognizes the important role of emotion, values and leadership oriented to support positive and creative behavior [22]. Leader motivates and inspires followers to execute job beyond the expectation. Leader also helps followers achieve the maximum potential to reach outcome of organization. The theory has attracted interest of scholars and has been one of the most dominant leadership theories [23]. Exploring the effect of transformational leadership and knowledge sharing gives important role in finding an effective way to promote knowledge sharing among members of organization.

Knowledge sharing is a process of knowledge exchange creating new knowledge among members of organization [24]. Knowledge sharing process is divided into two: knowledge donation and knowledge collection. Knowledge donation describes individual level that is voluntaire and proactive in communicating or supplying private intellectual capital to other members of organization. While knowledge collecting refers to readiness level of other members of organization to give skill and information to individuals when asking.

Empirical researches concerning the relationship between transformational leadership and knowledge sharing is still scarce and limited. However, the topic attracts attention of scholars. [25] supposed that transformational leadership manages knowledge and supportive culture forming employees behavior to activity of knowledge sharing by developing values, assumptions and beliefs related with knowledge. [26] indicated that transformational leadership that is successful in stimulating intellectual and inspiring followers will have positive effect to knowledge sharing behavior.

A number of researches showed that transformational leadership has significant effect to knowledge sharing.
Research finding of [27] indicated that transformational leadership is as potential predictor of organizational knowledge sharing. Meanwhile, the research result of [28] showed that all dimensions of transformational leadership have significant effect to knowledge management dimensions and one of the dimensions is knowledge sharing. [29] investigated leadership behavior and knowledge management practices in small enterprises in Australia. The finding indicated that transformational and transactional leadership positively and significantly affect to knowledge management practices. The same result is found by [5].

[30] studied about transformational and transactional leadership on knowledge management activity. Respondents are 215 librarians di universities in Nigeria. The research finding indicated that both leadership significantly affected to knowledge management activities. Idealized influence, inspirational motivation and individual consideration significantly affected to knowledge management activities. Idealized influence and individual consideration had the biggest effect to process of knowledge management. While for intellectual stimulation dimension, it is not accepted. For transactional leadership, it is just contingent reward affecting process of knowledge management.

Based on theoretical and empirical elaboration, the first hypothesis is idealized influence transformational leadership positively affects to knowledge sharing.

\section{E. Contingent Reward Transactional Leadership and Knowledge Sharing}

Employees need motivation from their leader to share knowledge. Reward system is a key factor to succeed knowledge sharing in organization. [31] found positive effect between reward and knowledge sharing. [32] studying 227 respondents using structural equation model found that selfmanagement leadership style, one of them is transactional leadership has positive effect to some dimensions of knowledge acquisition. Moreover [33] stated that an employee need strong motivation to share knowledge. It is not realisitic that all employees will share their knowledge easily without considering what will be gained. A manager should consider the importance of collaboration and best practices when designing reward system. The idea is to introduce a process how information and horizontal communication is supported and given a reward. Reward should be based on group performance, not individual [34].

[35] examined the relationship between leadership behavior and knowledge sharing in professional service companies in Taiwan and US. One of the results indicated that contingent reward leadership positively and significantly affects to knowledge sharing, internally as well externally. While [36] argued that economic exchange theory postulated that someone behaves such a way after considering the reward expected and cost spent. Relating with the matter, [37] explained that management should have a good system to give extrinsic rewards, like: salary, bonus, incentive to support knowledge sharing activities.

Research finding of [1] indicated that contingent reward leadership is significant predictor of knowledge sharing. The 
same result found by [29] that contingent reward behavior contributes to organizational knowledge creation and managerial mindset promoting information flow throughout organization. Contribution of contingent reward leadership to all dimensions of knowledge management practice seem bigger than that of charismatic one. With the leadership, employees are motivated and directed to gain performance standard expected to receive reward promised. Expected performance standard can involve satisfying performance, salary increase, oral appreciation, recognition and better job assignment [38]. Based on theoretical and empirical elaboration, the second hypothesis is contingent reward transactional leadership has positive effect to knowledge sharing.

\section{METHOD}

Lecturers from private universities with A institution accredition in LLDikti VI Central Java will be the population. The sample of the current research is part of the population determined using certain technique. Non probability sampling is used to take sample. The reason to use the approach is that the population is homogeneus in nature. To get representative sample, researcher distributes 300 questionnaires. Of 300 distributed, 224 returned. After data screening, 162 respondents can be used for next analysis.

Knowledge sharing is measured by using 5 indicators. The indicators are adapted from work of [39]. Meanwhile for idealized influence transformational leadership, the measurement is adapted from [40]. For contingent reward transactional leadership, the measurement is adapted from work of [22] and [41], based on work of [42]. All statements in questionnaires has scale 1 , not agree very much to scale 7 , agree very much.

\section{RESULT OF RESEARCH}

Before being conducted data analysis, instrument test is carried out. Base on validity and reliability test, it is known that the instruments used in the current research are valid and reliable. It is indicated by cronbach's alpha value up to 0.6 . The next step is model test. From model test conducted, the model is fit and can be used for next analysis. It is indicated from significant value that is 0.02 under $0.05 \%$ fixed. From t test, idealized influence transformational leadership has positive and significant effect to knowledge sharing. The indication can be seen from significant level of 0.01 lower than $0.05 \%$. While for contingent reward transactional leadership, the result is not significant. It is seen from significant level 0.203 higher than $0.05 \%$ fixed.

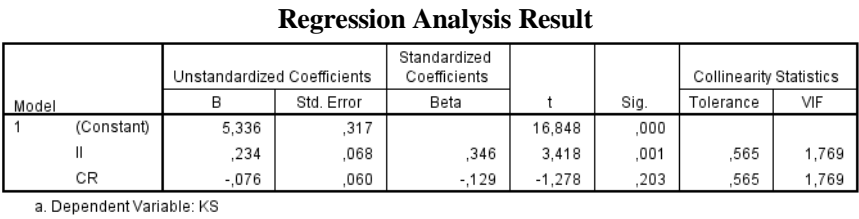

\section{DISCUSSION}

Based on multiple regression analysis, it is indicated that idealized influence transformational leadership positively and significantly affects to knowledge sharing. Meanwhile for contingent reward transactional leadership, the current research fail proving the positive effect to knowledge sharing.

\section{A. Idealized Influence Transformational Leadership and Knowledge Sharing}

The finding indicates that idealized influenced showed by dean as faculty leader supports lecturers to do knowledge sharing. The finding strengthens one of two main flows of the relationship that the relationship between the two can be direct and indirect and the current research proved that the relationship between transformational leadership and knowledge sharing is direct one.

Based on respondents's responses, dean is perceived to practice idealized influence leadership rating 85, 362 (high category). It is higher than score of contingent reward leadership of dean perceived by the respondents, 81,993. The finding is in line with literature about transformational and transactional leadership that generally effectivity of transformational leadership is higher than that of transactional one. However, in many previous researches, contingent reward leadership affect as strong as transformational leadership dimensions.

The research finding supported many previous researches. [43] conducted research concerning transformational leadership and knowledge sharing in Iraq universities. The research findings showed that idealized influence leadership positively affects to knowledge sharing. Leader showing the behavior has capability to give added value to institution activities, through creating, sharing, codifying and integrating, whether it is tacit as well as explicit. Transformational leadership using the dimension can build trust-based culture. In high trust culture, knowledge sharing will be conducive. It implies for lecturers and decision maker in higher education. Transformational leadership has capability to create trust culture and affective commitment to support employees sharing knowledge. The leader can support faculty to practice knowledge sharing through lecturing, workshop and other communication media to share knowledge and experience.

The other research is conducted by [30] studying about transformational and transactional leadership to knowledge management activity. The finding indicated that both, transformational and transactional leadership significantly affect to knowledge management process. Dimensions of idealized influence, inspirational motivation and individual consideration significantly affect to knowledge management process. Idealized influence and individual consideration leadership are the biggest effect to knowledge management process.

While [44] evaluated the effect of transformational leadership to knowledge sharing. The research evaluates 4 dimensions of transformational leadership, namely: idealized influence, inspirational motivation, intellectual stimulation and individualized consideration on knowledge sharing (knowledge donating and collecting). Respondents are 250 lecturers from Iraq state universities. The research finding showed that idealized influence positively affect to knowledge sharing. [4] studied concerning how individual dimension in transformational leadership theory contributed to knowledge 
sharing. The research findings showed that idealized influence leadership is as knowledge sharing predictor. The findings indicated that a leader with good respect, trust, self-confident [45] will affect to knowledge sharing. The research finding is in line with research of [46] that trust environment promoting knowledge sharing is always promoted by a leader with idealized influence. The positive effect of idealized influence leadership to knowledge sharing can be explained that when a leader sacrifices his own interest for organizational goodness, the followers will follow [47].

\section{B. Contingent Reward Transactional Leadership and Knowledge Sharing}

Based on hypothesis test, it is known that contingent reward leadership does not affect to knowledge sharing. The findings gives clearer description about the relationship between transactional leadership and knowledge sharing that is more various. A number of researches indicated significant effect [1]; [48]; [2]; [30], other researches are not significant [26].

From data of respondents, it is known that index rate of contingent reward of dean perceived by lecturers is 81,993 . The rate is categorized high. High perception of dean contingent reward transactional leadership does not support lecturers to share knowledge. If observed deeper, profession of lecturers has specification compared with other profession. Daily lecturers are within academic environment. The profession is familiar with sharing knowledge, whether to his students or his other stakeholders. It gives indication that activity of sharing knowledge can be inherent to the profession. The indication is known from response of respondents in open questionsn that they will share the knowledge though not asked.

From lecturer response, it is also known that dean as their leader give intrinsic reward compared with extrinsic one. From condition of research object, finance system is central in university. The fact can be one of the factors that the contingent reward leadership is not effective in faculty level. The other finding is that lecturers share the knowledge voluntarily. Besides, lecturers share knowledge because it is triggered by religion reason. It is relevant with universities being the object of the research that four of five universities are religion-based universities.

The indication is supported by many previous researches. [49] studied factors affecting knowledge sharing among academicians in Bowen University Nigeria. The result shows that reward system does not affect to knowledge sharing in university. The finding is also in line with research result of [50] that extrinsic reward is no effect to knowledge sharing. The research is conducted in Malaysia state as one universities where respondents are dominated by moslems, in which sharing knowledge is one of moslem obligations. The research of [49] is conducted in private university belonging to Christian foundation. Thus, the majority of respondents are Christian in faith. The indication is supported by respondent response that they share knowledge because of religion reason.

Meanwhile [51] studied the effect of extrinsic and intrinsic motivation to knowledge sharing in civil officers Nigeria. The research also find that organizational reward does not affect knowledge sharing significantly. The research finding is contradictive with the previous researches [31]; [52] finding that organizational reward is important to improve knowledge sharing culture. Meanwhile, [53] found that employees with intrinsic motivation will be more motivated to share knowledge than extrinsic one. As conclusion, it is better for an organization not just to focus on extrinsic reward. Combination of both will be more effective. Extrinsic reward is for shortterm purpose, while intrinsic one is for longer term.

\section{CONCLUSION}

From elaboration of the previous part, it is concluded that idealized influence transformational leadership has positive effect to knowledge sharing. Lecturers perceived dean as their leader play idealized influence transformational leadership. The role of dean leadership contributes to knowledge sharing of lecturers. Meanwhile the current research fail proving the effect of contingent reward transactional leadership to knowledge sharing. Though lecturers perceived dean to practice contingent reward leadership, such condition does not support lecturers to do knowledge sharing. There is indication that lecturers share knowledge voluntarily. Knowledge sharing is inherent obligation for lecturers. Reason of religion is also found. It is locic that four of five universities being object of the research are religion-based universities.

The current research gives theoretical contribution by giving more evidence of the effect of idealized influence dimension of transformational leadership to the knowledge sharing. For practical contribution, an organization should develop idealized influence leadership through intensive training to improve knowledge sharing. There are many limitations to be note. The object is only private universities so that the finding cannot be generalized into state universities too. Future research can compare between private and state universities to give comprehensive understanding concerning how knowledge sharing activities are encouraged. Future research can use other dimensions of transformational leadership to give better understanding of contribution of each dimension to knowledge sharing.

\section{REFERENCES}

[1] Chen. L.Y. dan Barnes. F.B. "Leadership behaviors and knowledge sharing in professional service firms engaged in strategic alliances." The journal of applied management and entrepreneurship, 2006. Vol. 11 No 2

[2] Masa'deh. R. et al. "A Jordanian empirical study of the associstions among transformational leadership, transactional leaderhip, knowledge sharing, job performance and firm performance." Journal of management development. 2016, Vol 35 no 5, pp. 681-705

[3] Al-husseini, S. and Elbeltagi, I. "Application of structural equation modelling to evaluate the effect of transformational leadership on knowledge sharing." University of Plymouth, School of Management, UK. 2014.

[4] Agyemang, F.G., Boateng, H., Dzandu, M.D. "Examining intellectua stimullation, idealised influence and individualised consideration as an antecedent to knowledge sharing: evidence from Ghana." Knowledge management and e-learning. 2017, Vol 9, no. 4, pp. 484-498

[5] Analoui, B.D., Doloriert, C.H., Sambrook, S. "Leadership and knowledge management in UK ICT organizations." Journal of management development. 2013, Vol. 32, No. 1, pp. 4-17. 
[6] Zhang, X. \& Jiang, J.Y. "With whom shall I share my knowledge? A recipient perspective of knowledge." Journal of knowledge management. 2015, Vol. 19, issue. 2, pp. 277-295.

[7] Law, C.H. \& Ngai, W.T. "An empirical study of the effects of knowledge sharing \& learning behaviors on firm performance." Expert systems with applications. 2008, Vol. 34, issue. 4, pp. 2342-2349.

[8] Jackson, S.E. et.al. "Toward developing human resource management systems for knowledge-intensive teamwork." Research in Personnel and Human Resource Management, 2006, Vol. 25, pp. 27-70.

[9] Yu, C. et.al. "Knowledge sharing , organizational climate and innovative behavior: A cross-level analysis of effects." Social Behavior and Personality, 2013, 41(1), 143-156.

[10] Ling, C.W. et.al. "Knowledge sharing in an American multinationa company based in Malaysia.” J. Workplace Learn, 2009, 21(2): 125-142.

[11] Islam, Z. et.al. "The mediating effects of socialization on organizational contexts and knowledge sharing." Journal of Knowl. Global, 2010, 3(1): 31-48.

[12] Peng, W. "Research on the influence of contextual performance based on the employee's social network feature and knowledge sharing." Sun Yatsen University, Guangzhou, 2010.

[13] Burns, J.M. "Leadership.” New York: Harper \& Row. 1978.

[14] Bass, B.M. "Leadership and performance beyond expectations." The Free Press, New York, NY. 1985.

[15] Long, C. et.al. "The impact of transformational leadership style on job satisfaction. World Applied Sciences Journal, 2014, Vol. 29, No. 1, pp. 117-124.

[16] Ivey, G.W. \& Kline, T. "Transformational \& Active Transactional leadership in the Canadian military." Leadership and organizational development journal, 2010, Vol. 31, issue: 3, pp. 246-262.

[17] Cheung, M.F.Y. and Wong, C.S. "Transformational leadership, leader support and employee creativity." Leadership and Organization Development Journal, 2011, Vol. 32, No. 7, pp. 656-672.

[18] Omar, W. and Hussin, F. "Transformational leadership style and job satisfaction relation: a study of structural equation modeling." International Journal of Academic Research in Business and Social Science, 2013, Vol. 3, No. 2, pp. 346-365.

[19] Humphries, J. "Transformational and transactional leader behavior." Journal of Management Research, 2001, (1)3, 149-159.

[20] Bryant, S.E. "The role of transformational and transactional leadership in creating, sharing and exploiting organizational knowledge." The journal of leadership and organizational studies. 2003, Vol 9(3).

[21] Podsakoff, P.M. et al. "Transformational leader behaviors and sustitutes for leadership as determinants of employee satisfaction, commitment, trust and OCB." Journal of Management, 1996, Vol. 22, No. 2, pp 259298.

[22] Bass, B.M. and Avolio, B.J. "MLQ: Multifactor Leadership Questionnaire" Mind Garden, 2000

[23] Mhatre, K.H and Riggio, R.E. "Charismatic and transformational leadership: past, present and future. The Oxford Handbook of Leadership and Organization." Oxford University Press, 2014, pp. 221-240.

[24] Van den Hooff, B. and de Ridder, J. A. "Knowledge sharing in context: the influence of organizational commitment, communication climate and CMC use on knowledge sharing." Journal of Knowledge Management., 2004, Vol. 8, No. 6, pp. 117-130.

[25] Birasnav, M. et.al. "Transformational leadership and human capital benefits: the role of knowledge management." Leadership and Organization Development Journal. 2011, Vol. 32, No. 2, pp. 106-126.

[26] Rawung, F.H. et.al. "The influence of transformational and transactional leadership on knowedge sharing : an empirical study on small and medium business in Indonesia." Asian academy of Management Journal, 2015, Vol. 20, No. 1, pp. 123-145.

[27] Barling, J. and Kelloway, E.K., "Young workers: varieties of experiences." American psychological association. Washington DC, 1999.

[28] Crawford, C.B. "Effects of transformational leadership and organizational position on knowledge management." Journal of knowledge management. 2005, Vol. 39, no. 6, pp. 6-16.

[29] Nguyen, H.N and Mohamed, S. "Leadership behaviors, organizational culture and knowledge management practices: An empirical investigation.” Journal of Management Development. 2011, Vol 30 no 2 , pp. 206-221.
[30] Ugwu dan Okore. "Transformational and transactional leadership influence on knowledge management activities of libraraians in university libraries." Journal of librarianship and information science. 2019, pp. 116.

[31] Bartol, K.M. and Locke, E.A. "Incentives and motivation." San Francisco. 2000, pp. 104-147

[32] Politis, J.D "The relationship of various leadership styles to knowledge management." leadership and organizational development journal, 2001, 22(8), pp. 354-364

[33] Syed-Ikhsan, S dan Rowland, F."Knowledge management in public organizations: a study on the relationship between organizational elements and the performance of knowledge transfer." Journal of knowledge management. 2004, Vol. 8, no 2, pp. 95-111.

[34] Goh, S.G. "Managing effective knowledge transfer: an integrative framework and some practice implications." Journal of knowledge management, 2002, 6(1), 22-30.

[35] Chen, L.Y. "An examination of the relationships among leaderships behaviors, knowledge sharing and marketing effectiveness in professional service firm that have been engaged in strategic alliances." Unpublished doctoral dissertation, Nova Southeastern University, 2004.

[36] Bock and Kim.'Breaking the myths of rewards: an exploratory study of attitudes about knowledge sharing." Information resource, Management Journal, 2002, Vol 15 no 2, pp. 14-21.

[37] Bartol, K.M. and Srivastava, A. "Encouraging knowledge sharing: the role of organizational reward systems." Journal of leadership and organizational studies. 2002, Vol. 9(1).

[38] Yulk, G. "Leaderhip in Organizational." Sixth Edition. New Jersey: Perason Prentice Hall, 2006.

[39] Vuori, V. and Okkonen, J. "Knowledge sharing motivational factors of using an intra organizational social media platform." Journal of knowledge management, 2012, 16(4), pp. 592-603.

[40] Bass, B.M. and Avolio, B.J. "Improving organizational effectiveness through transformational leadership." Sage, Thousand Oaks, CA. 1994.

[41] MacKenzie, S.B., Podsakoff, P. M., Rich, G.A. "Transformational and transactional leadership and salesperson performance." Journal of the academy of marketing science. 2001, Vol. 29, no. 2, pp. 115-134.

[42] Podsakoff, P. et al. "Situational moderators of leader reward and punishment behavior: fact or fiction?" Organizational Behavior and Human Performance, 1984, 34(1), pp. 21-63.

[43] Al-husseini, S. and Elbeltagi, I. "Application of structural equation modelling to evaluate the effect of transformational leadership on knowledge sharing." University of Plymouth, School of Management, UK, 2014.

[44] Al-husseini, S. and Elbeltagi, I. "Evaluating the effect of transformationa leadership on knowledge sharing using structural equation modelling: the case of Iraqi higher education." International journal of leadership in education. Theory and practice. Routledge. 2018.

[45] Avolio, B.J. and Bass, B.M. "Multifactor leadership questionnaire: Manual and sampler set." Redwood city, CA: Mind Garden, 2004.

[46] Jahani, S. et al. "Is reward system and leadership important in knowledge sharing among academics?" American journal of economics and business administration, 2011, 3(1), pp 87-94.

[47] Popper, M. and Lipchitz, M. "Installing mechanism and instilling values: the role of leaders in organizational learning." The learning organization, 2000, 7(3), pp. 135-144.

[48] Bradshaw, R., Chebbi, M., Oztel, H. "Leadership and knowledge sharing." Asian Journal of Business Research, Special Issue, 2015.

[49] Akosile dan Olatokun "Factors influencing among academics in Bowen University, Nigeria." Journal of librarianship and information science. 2019, pp. 1-18.

[50] Jolaee, A et al. "Factors affecting knowledge sharing intention among academic staff." International journal of educational management, 2014 28(4), pp. 413-431

[51] Olatokun, W. and Nwafor, C. "The effect of extrinsic and intrinsic motivation on knowledge sharing intentions of civil servants in Ebonyi State, Nigeria." Information development, 2011, pp. 1-19.

[52] Davenport, T.H and Prusak, L. "Working knowledge: How organization manage what they know." Harvard Business Press., 1998

[53] Osterloh, M. and Frey, B. "Motivation, knowledge transfer and organizational forms." Organization science, 2000, 11, pp. 538-550. 